\title{
An Improved Test to Study the Changes in Membrane Permeability During Rehydration of Freeze-Dried Weissella paramesenteroides LC11
}

\author{
A.A. Soro (née Yao)*,1, K.M. Djè ${ }^{1}$ and P. Thonart ${ }^{2,3}$ \\ ${ }^{I}$ Science and Food Technology Unit, University of Abobo-Adjamé, 02 BP 801 Abidjan 02, Côte d'Ivoire \\ ${ }^{2}$ Wallon Center for Industrial Biology, Microbial Technology Unit, University of Liège, Sart-Tilman B40, B-4000 Liège, \\ Belgium \\ ${ }^{3}$ Wallon Center for Industrial Biology, Bio-Industry Unit, Gembloux Agricultural University, Passage des déportés 2, B- \\ 5030 Gembloux, Belgium
}

\begin{abstract}
The objective of this study was to assess changes in membrane permeability during rehydration of freeze-dried Weissella paramesenteroides LC11. Viability was assessed using the electrical conductivity measurement ( $\mathrm{ms} \mathrm{cm}^{-1} \mathrm{~g}^{-1} \mathrm{dry}$ weight) and the plate count method ( $\mathrm{cfu} \mathrm{g}^{-1}$ dry weight). The symptoms of injury included an increase in the electrolyte leakage during the first $4 \mathrm{~h}$ of rehydration in Milli Q water and a decrease in the survival rate (about 64\%), suggesting an increase in membrane permeability during dehydration. During rehydration of the freeze-dried strain, an increase in the temperature, $\mathrm{NaCl}$ or monosodium glutamate concentration and a decrease in $\mathrm{H}^{+}$concentration resulted in an increase in the electrolyte leakage and a decrease in the survival rate (from about $5 \%$ to $97 \%$, with respect to the treatment made). However, a decrease in the electrolyte leakage was observed with increasing glycerol, sucrose or maltodextrin and resulted in the maintenance of cell viability. Change in membrane permeability might lead to electrolyte leakage during rehydration and, ultimately, cell death. The electrolyte leakage assay associated with the plate count method, a quick and inexpensive method, could be used to evaluate dried bacteria resistance to dehydration.
\end{abstract}

Keywords: Viability, starter culture, membrane integrity, freeze-drying, lactic acid bacteria, fermented foods.

\section{INTRODUCTION}

Freeze drying is commonly used to produce concentrated lactic acid bacteria (LAB) starter cultures for the food industry [1]. After dehydration, one population of microorganisms might be killed, another population might survive (noninjured), and a third might be sub-lethally injured. It is now generally agreed that the cell membrane is the component most commonly affected after a sub-lethal injury. Santivarangkna [2] and Brennan [3] indicated that a substantial alteration of membrane structure occurs in dried Lactobacillus Helveticus and Lb. acidophilus, respectively. These authors indicated that Leakage of the cell membrane was indirectly evident by an increase in cellular components such as enzymes and UV-absorbing materials in the surrounding medium after rehydration of dried cells, or by an increase in the cells' sensitivity to chemicals such as $\mathrm{NaCl}$, oxgall and lysozyme. To evaluate dried bacteria resistance to dehydration and control changes in membrane permeability through the use of additives, it would be necessary to conduct a quick and inexpensive method immediately after the drying process. Most studies performed to determine the efficiency of conservation methods are based on the survival rate of the dried bacteria. However, cell viability can also be determined by measuring the electrochemical characteristics of the culture medium, which are related to both the number

*Address correspondence to this author at the Science and Food Technology Unit, University of Abobo-Adjamé, 02 BP 801 Abidjan 02, Côte d'Ivoire; Tel: +22520304240; Fax: +22520378118;

E-mail: amenansoro@yahoo.fr and the metabolic activity of the microorganisms [4]. The electrolyte leakage assay was used to evaluate the performance of freeze-dried $L b$. delbrueckii ssp. bulgaricus and LAB in milk $[4,5]$. Such measurements, however, have never been performed in combination with the survival rate to assess the change in membrane permeability during rehydration of freeze-dried LAB.

In this work, the viability of the freeze-dried $W$. paramesenteroides was evaluated by measuring electrolyte leakage and viable cell after the drying process. The effects of the $\mathrm{pH}$, temperature, $\mathrm{NaCl}$ or glycerol concentration, and sucrose, maltodextrin or monosodium glutamate concentration during rehydration of the freeze-dried strain were investigated. Previously, W. paramesenteroides LC11 had been isolated during cassava fermentation and was selected as a suitable starter culture for gari production [6-8].

\section{MATERIALS AND METHODS}

\section{Microorganism, Production and Freeze-Dying}

The LAB $W$. paramesenteroides LC11 was provided by the Federal Research Centre for Nutrition, Institute of Hygiene and Toxicology (Karlsruhe, Germany), produced in a $20 \mathrm{~L}$ bioreactor containing MRS medium for $18 \mathrm{~h}$, concentrated, and then freeze-dried as described previously by Yao [7].

\section{Experimental Procedure}

In order to determine the time course of electrolyte leakage during rehydration, $0.5 \mathrm{~g}$ of the dried sample (original 
concentration about $4.8 \times 10^{12}$ cfu g $^{-1}$ dry weight) was soaked in $10 \mathrm{~mL}$ Milli $\mathrm{Q}$ water for $8 \mathrm{~h}$ at room temperature. Samples were sampled every $2 \mathrm{~h}$ and analyzed for conductivity and viability. For the next steps of the experimental procedure $0.5 \mathrm{~g}$ was soaked in $10 \mathrm{~mL}$ Milli $\mathrm{Q}$ water for $2 \mathrm{~h}$, and then transferred into $10 \mathrm{~mL}$ Milli $\mathrm{Q}$ water for $4 \mathrm{~h}$ that had been obtained according to the designed parameter. The effect of each parameter was evaluated through conductivity and viable counts determinations in $20 \mathrm{~mL}$ total Milli Q water after $6 \mathrm{~h}$ (total experimental time) at room temperature. The effect of temperature was studied from $20^{\circ} \mathrm{C}$ to $40^{\circ} \mathrm{C}$ at $5^{\circ} \mathrm{C}$ intervals. The effect of $\mathrm{pH}$ was studied in a $10 \mathrm{ml}$ buffer solution $\left(0.1 \mathrm{M} \mathrm{KH}_{2} \mathrm{PO}_{4}\right.$ solution adjusted with $\left.0.1 \mathrm{~N} \mathrm{NaOH}\right)$ at $\mathrm{pH}$ 5.8, 6.2, 6.6, 7.0 and 7.4. The effect of glycerol, $\mathrm{NaCl}$, sucrose, maltodextrin or monosodium glutamate concentration was studied at 5, 15, 20, 30 and $40 \mathrm{~g} \mathrm{~L}^{-1}$. All the experiments were carried out aseptically $20 \mathrm{~h}$ after the freeze-drying process. Maltodextrin IT 12 or glycerol and Monosodium glutamate or all other chemicals were purchased from
Roquette (Lestren, France) and Sigma-Aldrich (Schnelldorf, Germany), respectively.

\section{Analyses}

The electrical conductivity ( $\mathrm{ms} \mathrm{cm}^{-1} \mathrm{~g}^{-1} \mathrm{DW}$ ) of the solution was measured using a ProfiLine Multi 197i (WTW $\mathrm{GmbH}$, Weilheim, Germany) conductivity meter. Total conductivity was obtained after autoclaving the samples at $112^{\circ} \mathrm{C}$ for $20 \mathrm{~min}$. The viable counts were obtained using the plate count method after $48 \mathrm{~h}$ at $30^{\circ} \mathrm{C}$ with MRS-agar medium ( $\mathrm{pH}$ 6.0). The dry cell weight was determined after drying at $105^{\circ} \mathrm{C}$ until constant weight.

\section{Data Analysis}

The percentage leakage was calculated using the ratio $\left(\mathrm{EC}_{\mathrm{f}}-\mathrm{EC}_{\mathrm{i}}\right) /\left(\mathrm{EC}_{\text {total }}-\mathrm{EC}_{\mathrm{i}}\right) \times 100$. The percentage leakage was expressed as percentage of total electrolytes after autoclaving the samples for this reason; after autoclaving, we expect that cells die, that means at first stage a decrease of the cells'
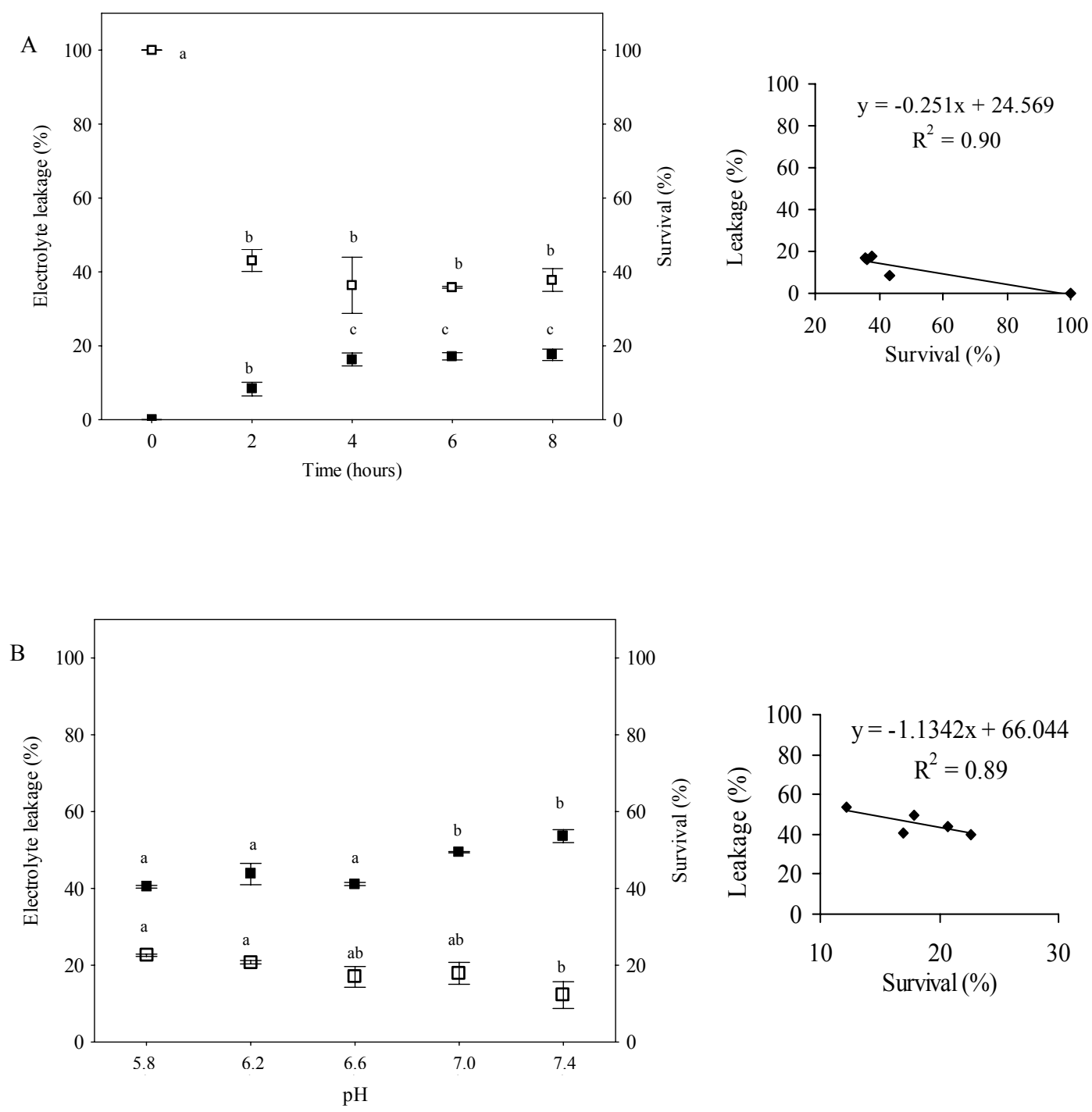

Fig. (1). Time course of (A) or Effect of external pH (B) on electrolyte leakage ( $\mathbf{\square})$ and survival ( $\square$ ) during rehydration of freeze-dried $W$. paramesenteroides in Milli Q water. Values are presented as means \pm standard deviation $(\mathrm{SD}, n=4)$. Mean values with a different letter for each parameter are significantly different (Tukey HSD test, $P<0.05$ ). Biological replicates have been used to calculate the mean values. 
membrane electrochemical potential to zero, which will result in a transient decrease of the total conductivity (dead cells) and ultimately to a full leakage of intracellular metabolites to the medium compared to the initial conductivity (i. e. experimental conductivity) (cells alive). The percentage survival was calculated as $\mathrm{N} / \mathrm{N}_{0} \times 100$. A regression analysis was made between the percentage leakage and the percentage survival, and the goodness-of-fit was confirmed by the $\mathrm{R}^{2}$. Productions in the bioreactor were done in duplicate. The data were compared using Tukey's honestly significant difference (Statistica 7.1, StatSoft Inc., 2005). The level of significance was set at $P<0.05$.

\section{RESULTS AND DISCUSSION}

The leakage of electrolytes from the freeze-dried $W$. paramesenteroides bacteria during rehydration in Milli $\mathrm{Q}$ water was a function of time (Fig. 1A). During the rehydration period, the percentage leakage increased significantly between the 2 nd and 4 th hour (from about $8 \%$ to $14 \%$ of total electrolytes) and then remained fairly constant up to $8 \mathrm{~h}(P<$ $0.05)$. The viable population of the freeze-dried strain was reduced from an initial population of $4.8 \times 10^{12} \mathrm{cfu} \mathrm{g}^{-1} \mathrm{DW}$ (viable count at the end of freeze-drying) to $1.8 \times 10^{12} \mathrm{cfu} \mathrm{g}^{-1}$ DW with a percentage survival of $36 \pm 5.4 \%$ after $4 \mathrm{~h}$ of rehydration. More than $90 \%$ of the variability in the percentage survival could be explained by the percentage leakage, as shown by the coefficient of determination of the regression lines $\left(\mathrm{R}^{2} \geq 0.9\right)$. However, the change in the percentage leakage for each unit change in the percentage survival is not significant as shown by the slopes of the lines which vary from 0.2 to 2.3. The electrolyte leakage assay can not be use alone as a predictor of cell viability. Our work suggests that $4 \mathrm{~h}$ was an appropriate time for an accurate measurement of electrolyte leakage from dried cells, since beyond this time there was no further increase in electrolytes efflux. In this way, the method became less time-consuming for routine work. The increase in the percentage leakage indicated that changes in membrane permeability of the dried strain might be induced by the rehydration treatment. It is possible that loss of membrane structure could lead to electrolyte leakage during rehydration and, ultimately, cell death. Our findings accord with the conclusion reached by others authors who showed that membrane damage was a catalyst of $\mathrm{Lb}$. acidophilus death during drying [3]. Because of an increase in cell rupture as a result of dehydration treatment the freezedried cells were incubated for $2 \mathrm{~h}$ before experiments. The percentage leakage or survival increased or decreased with decreasing $\mathrm{H}^{+}$concentration in the solution, respectively (Fig. 1B). For example, the percentage leakage increased significantly from pH 6.6 to 7.4 by $13 \%$ of total electrolytes with a decrease in the viable population of about $5 \%(P<$ $0.05)$. The dehydration stress could increase the rate of passive diffusion across the phospholipid bilayer. In cell membranes, $\mathrm{K}^{+}$and $\mathrm{Na}^{+}$are believed to be transported across the plasma membrane by an ionic pump which transports $\mathrm{K}^{+}$into the cell and $\mathrm{Na}^{+}$out of it, in both cases, against its electrochemical gradient [9]. This results in a difference in chemical potential across the membrane, which represents a delicate balance in selective permeability and concentration gradients. An increase in membrane permeability might lead to a decrease in electrical charge across the membrane and, ultimately, cell death. Alternatively, an increase in electro- lyte leakage would occur if the activity or the efficiency of the transport system had been altered. Whether or not these changes are related to the freeze-drying process remains to be established. The percentage leakage increased significantly from $20^{\circ} \mathrm{C}$ to $40^{\circ} \mathrm{C}$ by $13 \%$ of total electrolytes, with a decrease in viable population of about $32 \%$ (Fig. 2A) $(P<$ 0.05). An increase in the percentage leakage, with an increase in the rehydration temperature, would occur if the integrity of the membrane was altered. An increase in $\mathrm{NaCl}$ or glycerol concentrations (from $5 \mathrm{~g} \mathrm{~L}^{-1}$ to $40 \mathrm{~g} \mathrm{~L}^{-1}$ ) was associated with a decrease in osmotic pressure from -3.6 to 4.2 $\mathrm{Pa}$ or from -3.2 to $-5.3 \mathrm{~Pa}$, respectively (data not shown). The osmotic pressure data given are only approximate, since they do not take into consideration those of the dried powder. The percentage leakage increased with increasing $\mathrm{NaCl}$ concentration and could indicate that electrolytes efflux might be imposed by the osmotic gradient (Fig. 2B). While an increase in $\mathrm{NaCl}$ concentration was associated with a decrease in viability, that of glycerol resulted in the maintenance of cell viability or a better viability (Fig. 2C). For example, $7 \%$ leakage and $40 \%$ survival rate were achieved with $40 \mathrm{~g} \mathrm{~L}^{-1}$ glycerol, compared with $81 \%$ leakage and $3 \%$ survival rate with $40 \mathrm{~g} \mathrm{~L}^{-1} \mathrm{NaCl}$, after $4 \mathrm{~h}$ of rehydration. The sensitivity of the freeze-dried $W$. paramesenteroides to an increase in $\mathrm{NaCl}$ concentration could also indicate damage to cell membrane components. It is possible that the presence of glycerol makes the bacterial membrane less permeable and therefore it might improve the viability. Figs. (3A or 3B) shows that the percentage leakage decreased as the concentration of sucrose or maltodextrin increased (from $5 \mathrm{~g} \mathrm{~L}^{-1}$ to $40 \mathrm{~g} \mathrm{~L}^{-1}$ ), respectively. At $40 \mathrm{~g} \mathrm{~L}^{-1}$ concentration, a higher percentage survival and a lower percentage leakage were obtained with maltodextrin $(48 \%$ and $1 \%$, respectively), followed by sucrose ( $45 \%$ and $4 \%$, respectively). These results are consistent with those obtained above on the effect of an increase in glycerol concentration. In contrast, an increase in monosodium glutamate concentration resulted in an increase in the percentage leakage and a decrease in viability in the same range of concentration (Fig. 3C). Sucrose, maltodextrin and monosodium glutamate are commonly used as protective compounds in the freeze-drying process [10]. Our results suggest that increasing the number of $\mathrm{OH}$ groups in the rehydration solution might make the membrane less permeable to electrolytes and could improve or maintain the viability, possibly by protecting membrane phospholipids. These results accord with those reported by other authors, who have shown that the direct interaction between sucrose and membrane might contribute to the protective effects of sucrose on the dried cells of Lb. Bulgaricus [10]. These authors suggested that $\mathrm{OH}$ groups of sugar and/or polyalcohol could replace water and could interact with phospholipids to maintain membrane integrity.

\section{CONCLUSION}

Changes in membrane permeability of the freeze-dried $W$. paramesenteroides was assessed by measuring electrolyte leakage and viable cells during rehydration. An increase in the leakage of solutes from the dried strain was correlated with a decrease in viable cell during rehydration. The dehydration process might increased the incidence of cell rupture during rehydration. Our results confirm the importance of cryoprotectants in the protection of the bacterial membranes 

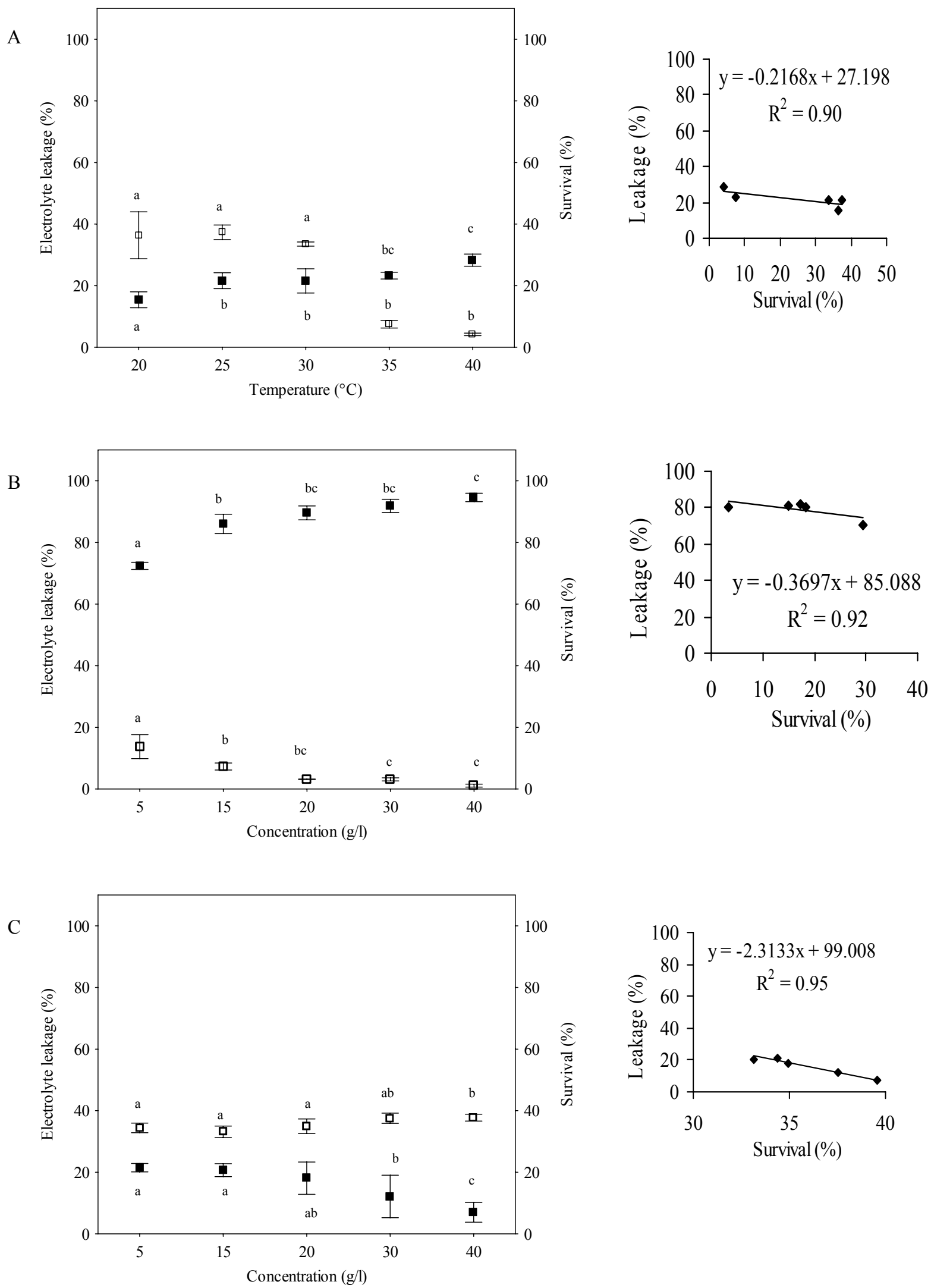

Fig. (2). Effect of temperature (A) and $\mathrm{NaCl}(\mathbf{B})$ or glycerol (C) concentration on electrolyte leakage (অ) and survival ( $\square$ ) during rehydration of freeze-dried $W$. paramesenteroides. Values are presented as means \pm SD $(n=4)$. Mean values with a different letter for each parameter are significantly different (Tukey HSD test, $P<0.05$ ). Biological replicates have been used to calculate the mean values. 

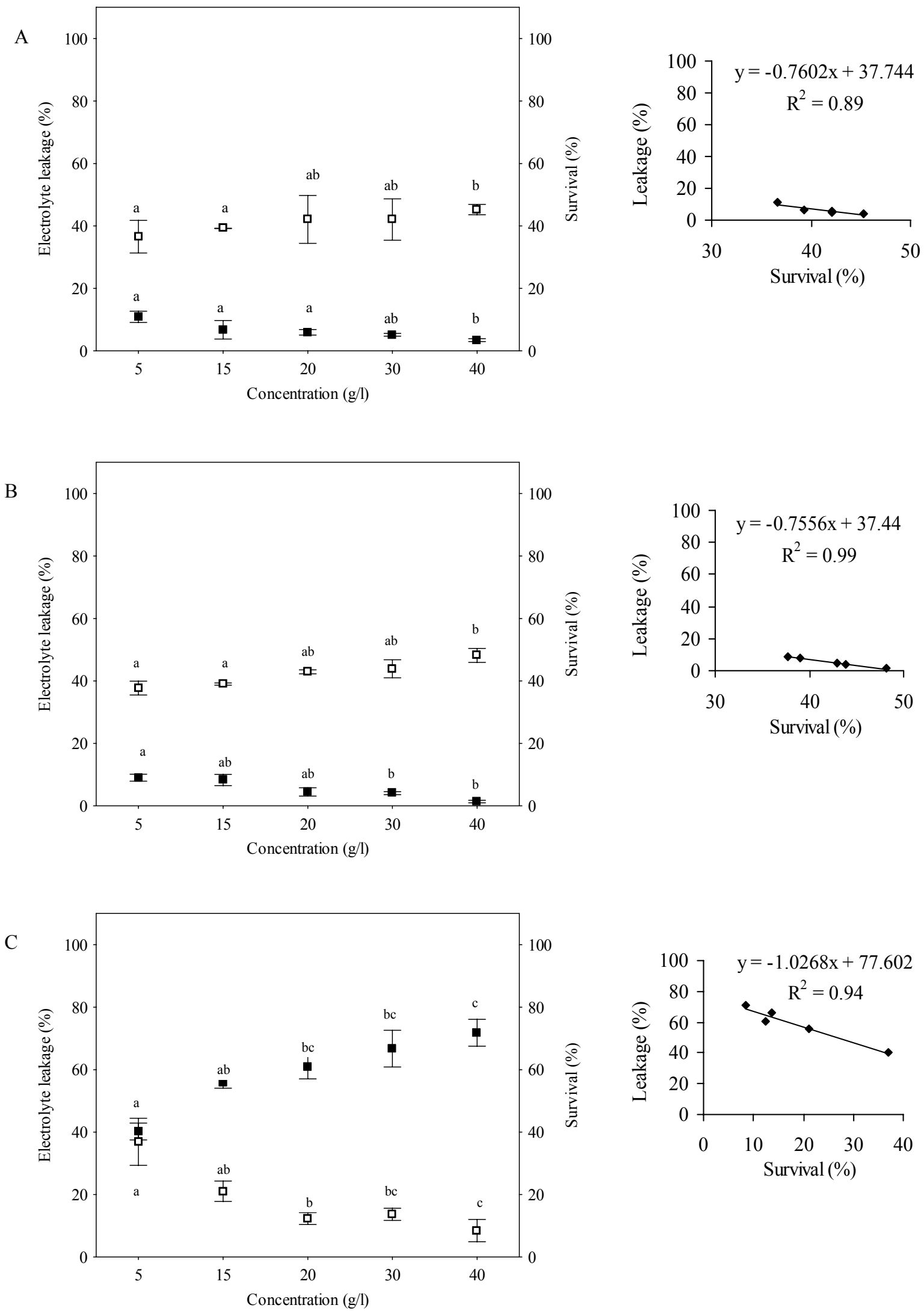

Fig. (3). Effect of sucrose (A), maltodextrin (B) and monosodium glutamate (C) concentration on electrolyte leakage ( $\square)$ and survival ( $\square$ ) during rehydration of freeze-dried $W$. paramesenteroides. Values are presented as means \pm SD $(n=4)$. Mean values with a different letter for each parameter are significantly different (Tukey HSD test, $P<0.05$ ). Biological replicates have been used to calculate the mean values. 
to prevent sublethal membrane damage during freezing and minimize subsequent cellular injuries during subsequent rehydratation. The electrolyte leakage assay associated with the plate count method, could be used as a predictive test for the description of dehydration inactivation of dried bacteria.

\section{ACKNOWLEDGEMENTS}

We gratefully acknowledge the Federal Research Centre for Nutrition, Institute of Hygiene and Toxicology (Karlsruhe, Germany) for providing W. paramesenteroides LC11.

\section{ABBREVIATIONS}

$\begin{array}{ll}\mathrm{DW} & =\text { dry weight } \\ \mathrm{EC}_{\mathrm{f}} & =\text { electrical conductivity after } 4 \mathrm{~h} \text { rehydration } \\ \mathrm{EC}_{\mathrm{i}} & =\begin{array}{l}\text { electrical conductivity at the beginning of the } \\ \text { experiment }\end{array} \\ \mathrm{EC}_{\text {total }} & =\begin{array}{l}\text { electrical conductivity after autoclaving the } \\ \text { sample during } 20 \text { min at } 112^{\circ} \mathrm{C}\end{array} \\ \mathrm{LAB} & =\text { lactic acid bacteria } \\ \mathrm{N} & =\text { cell count at each storage time } \\ \mathrm{N}_{0} & =\text { cell count at the end of freeze-drying } \\ \mathrm{R}^{2} & =\text { coefficient of determination }\end{array}$

\section{REFERENCES}

[1] Ziadi M, M'hir S, Abdeslam M, Thonart P, Hamdi M. Production and freeze-drying of Leben starter culture. Res J Microbiol 2009; 4(1): 31-7.

[2] Santivarangkna C, Wenning M, Foerst P, Kulozik U. Damage of cell envelope of Lactobacillus helveticus during vacuum drying. J Appl Microbiol 2007; 102(3): 748-56.

[3] Brennan M, Wanismail B, Ray B. Cellular damage in dried Lactobacillus acidophilus. J Food Prot 1986; 49 (1): 47-53.

[4] Lanzanova M, Muchetti G, Neviani E. Analysis of conductance changes as a growth index of lactic acid bacteria in milk. J Dairy Sci 1993; 76(1): 20-8.

[5] Martos GI, Ruiz Holgado AP, Oliver G, De Valdez G. Use of conductimetry to evaluate Lactobacillus delbrueckii ssp. bulgaricus subjected to freeze-drying. Milschwissenschaft 1998; 53(3): 12830 .

[6] Kostinek M, Specht I, Edward VA, et al. Characterisation and biochemical properties of predominant lactic acid bacteria from fermenting cassava for selection as starter cultures. Int J Food Microbiol 2007; 114(3): 342-51.

[7] Yao AA, Bera F, Franz CAMP, Holzapfel WH, Thonart P. Survival rate analysis of freeze-dried lactic acid bacteria using the Arrhenius and z-value models. J Food Prot 2008; 71(2): 431-4.

[8] Yao AA, Dortu C, Egounlety M, et al. Production of freeze-dried lactic acid bacteria starter culture for cassava fermentation into gari. Afr J Biotechnol 2009; 8(19): 4996-5004.

[9] Yeagle PL. In: Yeagle PL, Ed. Transport. The Membranes of cells. New-York: Academic Press 1993; pp. 231-58.

[10] Oldenhof H, Wolkers WF, Fonseca F, Passot S, Marin M. Effect of sucrose and maltodextrin on the physical properties and survival of air-dried Lactobacillus bulgaricus: an in situ Fourier transform infrared spectroscopy study. Biotechnol Prog 2005; 21(3): 885-92. 